\title{
EREBEA
}

\author{
Revista de Humanidades \\ y Ciencias Sociales \\ Núm. 8 (2018), pp. 231-246 \\ ISSN: 0214-0691
}

\section{El VALOR COGNITIVO DE LAS METÁFORAS EN LA COMUNICACIÓN PÚBLICA DE LAS CIENCIAS}

\author{
María Gabriela Ramos, Andrea B. Pac, Verónica B. Corbacho, \\ Franco A. Trinidad, Andrés E. Oliva \\ Universidad Nacional de la Patagonia Austral \\ Unidad Académica Río Gallegos (UNPA UARG)
}

RESUMEN

La Comunicación Pública de las Ciencias se desarrolla en la teoría de la comunicación y en las prácticas de comunicadores y científicos. Estos últimos asumen cada vez más la difusión de sus investigaciones. La metáfora se considera una herramienta útil para la enseñanza y la difusión del conocimiento. Este trabajo adopta la perspectiva del valor cognitivo de la metáfora en convergencia con el modelo etnográfico contextual para analizar el uso de las metáforas en las tapas y contenido de una colección de divulgación escrita por científicos. El análisis muestra que la tarea asumida por los científicos no es sencilla y aún se observa que no se valora completamente el potencial cognitivo de la metáfora y una fluctuación entre el modelo del déficit y el modelo del diálogo.

Palabras Clave

Metáforas; valor cognitivo; comunicación pública; ciencias; diálogo.

Fecha de recepción: 8 de oct. de 2018

Fecha de aceptación: 30 de nov. de 2018

\section{Abstract}

Public Communication of Science is developed in Communicational Theory as well as in the practice of communicators and scientists. The latter tend to undertake the task of spreading their investigations. Metaphors have been commonly considered to be useful tools for teaching and spreading knowledge. This paper assumes the perspective of metaphor's cognitive value together with the contextual ethnographic model to analyze the use of metaphors in the covers and contents of a divulgation collection written by scientists. The analysis shows that the role assumed by scientists as communicators is not a simple one. It is noted that the cognitive value of metaphor is not still fully recognized. This results in a fluctuation between the Deficit Model and the Dialogue Model.

\footnotetext{
KeYwords

metaphors; cognitive value; public communication; sciences; dialogue.
} 


\section{INTRODUCCIÓN}

El campo de la Comunicación Pública de la Ciencia (en adelante CPC) ha evolucionado desde la concepción del modelo del déficit a una perspectiva enmarcada fundamentalmente en el diálogo ${ }^{1}$. El primero

reproduce (...) el esquema unidireccional overtical del proceso de comunicación entendido como la transmisión de información desde un sujeto que dispone de un determinado conocimiento -el científico individual, la comunidad científica como emisor colectivo- hacia otro que carece de él -el público lego- ${ }^{2}$.

Este modelo supone una asimetría irreductible entre el científico o el académico y el lego ${ }^{3}$.

En contraposición, el modelo etnográfico-contextual ${ }^{4} \mathrm{o}$ "Modelo de las Tres D” por contemplar el Diálogo, el Debate y la Discusión como sus componentes principales. En la interrelación de estos procesos que se dan alrededor de la comunicación de las ciencias, se concibe a los destinatarios como sujetos reflexivos y críticos que forman parte de diferentes contextos socio-culturales. Este modelo tiene en cuenta las representaciones sociales que tienen científicos y público tanto uno del otro como de sí mismo en su relación con el conocimiento 5 .

En los últimos, años el científico se vio, cada vez más, convocado por la sociedad a comunicar los procesos y resultados que obtenía en las universidades y centros de investigación, en diferentes contextos y a destinatarios diversos. El investigador ya no sólo produce conocimiento sino que también debe abrirlo a un público que espera comunicarse con él: "quien produce conocimiento asume, o es inducido a asumir, que su función ya no puede reducirse a ello sino que también debe adquirir un grado de experticia para su transmisión social”' En su afán de

1 Cf. C. Cortassa, "Del déficit al diálogo, ¿y después? Una reconstrucción crítica de los estudios de comprensión pública de la ciencia", en Revista CTS No 15, Volumen 5 (2010), pp. 47-72. Disponible en www.revistacts.net/files/Volumen\%205\%20-\%20Número\%2015/cortassa_edit. pdf.

2 C. Cortassa, La ciencia ante el público. Dimensiones epistémicas y culturales de la comprensión pública de la ciencia. Buenos Aires: Eudeba, 2012, p. 55.

3 Cf. Cortassa, "Del déficit al diálogo...".

4 Cf. A. Irwin y M. Michael, Science, Social Theory and Public Knowledge. Philadelphia: Open University Press, 2003; S. Miller, "Public understanding of science at the crossroads", en Public Understand. Sci. 10 (2001), pp. 115-120.

5 Cf. Cortassa, "Del déficit al diálogo...".

6 Cortassa, La ciencia ante el público..., p. 129. 
transmitir el conocimiento que produce, el científico se encuentra, por un lado, con el público destinatario y por otro con los mediadores (editores, periodistas, comunicadores), que lo sitúan en un rol complejo para el cual muchas veces le faltan elementos. La forma en la que cada uno entiende su función implica que no siempre se ponga el énfasis en los mismos aspectos o que los criterios no sean compartidos. La brevedad, simpleza del mensaje, fidelidad conceptual, no siempre tienen la misma importancia y significado para los distintos actores, y frecuentemente entran en conflicto.

El científico, en su rol de comunicador público de la ciencia, sabe que su destinatario no es un par. Sabe que necesita construcciones y expresiones distintas de las que habitualmente utiliza en su actividad académica. Las metáforas, en especial, son construcciones léxicas y visuales que, supone, lo ayudan a comunicarse con un público lego. Curiosamente, es posible que no perciba la presencia de metáforas en sus textos académicos, pero recurre a ellas explícitamente cuando se pone en rol de comunicador. En la teoría de las representaciones sociales, estas construcciones forman parte de un proceso de objetivación ${ }^{7}$ que consiste en sustituir el objeto de la representación por otro término o construcción próximo a la experiencia del grupo y reconocible por él. Es necesario, pues, determinar cuál es el valor cognitivo que se le otorga a las metáforas y desde qué paradigma de la CPC se sitúa el científico a la hora de comunicar en productos como las denominadas colecciones de divulgación científica.

Este debate epistemológico se reproduce al interior de la CPC. Algunos sostienen que, al hacer uso de distintas herramientas 'pedagógicas' como la metáfora, los científicos deben evitar reducirla a un mero recurso simplificador o retórico, y reconocer su valor en la construcción del conocimiento. Además, deben elegir metáforas cuidadosamente ya que, por un lado, la ambigüedad del lenguaje metafórico da lugar a variedad de interpretaciones y, por el otro, la interpretación técnica de un concepto en un área puede diferir sustancialmente de la que se da en el ámbito no científico; en ambos casos una metáfora puede causar mayor confusión si se presupone la universalidad de un significado.

Sin embargo, esta postura resulta demasiado cercana al modelo del déficit y hace pensar que, si bien en los últimos años el modelo de las tres $\mathrm{D}$ ganó espacio en la CPC, el modelo del déficit sigue presente en este ámbito y en la construcción del conocimiento científico en general. En primer lugar, supone que

7 La teoría de las representaciones sociales define dos tipos de funciones, la función cognitiva y la normalizadora. Dentro de la función cognitiva se distinguen dos procesos fundamentales: el anclaje y la objetivación: "las representaciones proveen de recursos cognitivos para enfrentar lo desconocido, disminuyendo el recelo que provoca: probablemente una de las afirmaciones más reiteradas en la literatura sea la expresión que cifra su propósito en términos de 'hacer familiar lo no-familiar'. Ese proceso de articulación de la información novedosa en esquemas previos se realiza a través de dos mecanismos: anclaje -anchoring-y objetivación -objectifying-" (Cortassa, "Del déficit al diálogo...”, p. 17). 
los científicos tienen un conocimiento que se expresa en términos no metafóricos sino 'técnicos' que necesitan hacer más accesible para el público, y que la metáfora es un recurso cuya función consiste sólo en ser vehículo de ese conocimiento. En segundo lugar, supone que esa definición técnica no opera según algún procedimiento metafórico. Por último, presupone que la metáfora es ajena a los conceptos en sentido estricto. Pareciera, pues, que el científico debiera hacer concesiones epistemológicas al momento de comunicar las ciencias. El alcance de las metáforas no es simplemente el de 'reducir' o 'simplificar', inclusive con el riesgo de 'desvirtuar' conceptos complejos, sino de producirlos.

La metáfora, afirman Lakoff y Johnson, "impregna la vida cotidiana, no solamente en el lenguaje, sino también el pensamiento y la acción. Nuestro sistema conceptual ordinario, en términos del cual pensamos y actuamos, es fundamentalmente de naturaleza metafórica" ${ }^{8}$. Las orientaciones arriba-abajo, atrás-adelante, las personificaciones y ontologizaciones, y las significaciones que se desplazan de unos campos semánticos a otros, organizan nuestro conocimiento de la realidad y producen las redes conceptuales que permiten pensarla y comunicarla, incluso de manera 'inequívoca'.

En el campo epistemológico Black ${ }^{9}$, Boyd ${ }^{10}$ y Palma $^{11}$ han defendido el valor cognitivo de la metáfora. Para nuestro análisis, y sin pretender una clasificación exacta ni exhaustiva, encontramos que los autores organizan las metáforas por su origen, por el contexto en que se utilizan, o por el tipo y alcance de la operación conceptual y la producción de sentido ${ }^{12}$.

En la perspectiva de su origen, las metáforas provienen de la interacción entre campos científicos, de la cultura ${ }^{13}$, o de "orientaciones espaciales [que] surgen del hecho de que tenemos cuerpos de un tipo determinado y que funcionan como funcionan en nuestro medio físico" ${ }^{14}$. Según el contexto de uso, pueden ser literarias, exegéticas o pedagógicas (enseñanza y divulgación ${ }^{15}$ ), o constitutivas

8 G. Lakoff et M. Johnson, Metáforas de la vida cotidiana. Madrid: Cátedra, 2004[1980], 379. 9 M. Black, Modelos y metáforas. Madrid: Tecnos, 1966.

10 R. Boyd, "Metaphor and Theory Change: what is 'metaphor' a metaphor for?", en A. Ortony (ed.) Metaphor and Thought. Cambridge: CUP, 1998.

11 H. Palma, Ciencia y metáforas. Critica de una razón incestuosa. Buenos Aires: Prometeo, 2015.

12 V. Corbacho, A. Ortiz, A. Pac, F. Trinidad, "La Inclusión de Analogías en las Planificaciones Docentes Experiencia en la Formación Inicial del Profesorado de Biología", en M. Plaza et al: Actas de XII Jornadas Nacionales. VII Congreso Internacional de Enseñanza de la Biología y III Congreso Internacional de Enseñanza de las Ciencias: Volver a las fuentes: la resignificación de la enseñanza de la biología en aulas reales. Córdoba: Asociación de Docentes de Ciencias Biológicas de la Argentina, 2016, pp. 1-2.

13 Palma, Ciencia y metáforas..., pp. 46-48.

14 Lakoff et Johnson, Metáforas de la..., p. 50.

15 Palma, Ciencia y metáforas..., p. 45. 
de teorías científicas ${ }^{16}$. Según la operación conceptual que las hace posible y la producción de sentido y conocimiento, las metáforas pueden ser sustitutivas de un término por otro ${ }^{17}$, sustitutivas de términos inexistentes (sobre todo en el caso de nuevas teorías $)^{18}$, comparativas $^{19}$, o interactivas ${ }^{20}$, como sin duda lo son las "grandes metáforas" ${ }^{21}$ y las ontologizaciones y personificaciones ${ }^{22}$.

En los últimos tiempos, la cantidad de textos de comunicación de las ciencias se ha multiplicado hasta llegar a ser abrumadora: desde columnas periodísticas escritas por periodistas especializados hasta libros destinados al público lego escritos por científicos de renombre. Las posibilidades son múltiples y variadas. El objetivo de este trabajo es explorar el rol de las metáforas en textos de difusión de las ciencias. El análisis se realiza sobre un corpus de publicaciones de editoriales universitarias escritas por científicos a fin de identificar cómo se construye el mensaje a nivel lingüístico, epistemológico y comunicacional. Para analizar el aspecto comunicacional exploramos el tipo de metáfora y su interacción con las audiencias.

\section{Metodología}

El corpus fue seleccionado de una serie de amplia circulación actual: la colección Ciencia que ladra (en adelante CQL), editada por la Universidad Nacional de Quilmes y Siglo XXI. Esta colección está escrita desde la perspectiva de un investigador que busca salir del ámbito científico para comunicar los conocimientos acerca de la naturaleza del mundo, así como intentar contagiar el interés que lo motiva. La nota del editor que se repite como cierre del prefacio de cada libro es ilustrativa de ello:

Esta colección de divulgación científica está escrita por científicos que creen que ya es hora de asomar la cabeza por fuera del laboratorio y contar las maravillas, grandezas y miserias de la profesión. Porque de eso se trata: de contar, de compartir, de saber que, si sigue encerrado, puede volverse inútil ${ }^{23}$.

El corpus fue clasificado de la siguiente manera: de una muestra de 62 libros disponibles de la colección CQL se estableció la distinción según temas y contenidos, entre textos dedicados a las ciencias naturales (42), textos destinados

16 Boyd, "Metaphor and Theory Change...", p. 485.

17 Black, Modelos y..., pp.42-46.

18 Boyd, "Metaphor and Theory Change...", p. 486.

19 Black, Modelos y..., pp. 46-47.

20 Black, Modelos y..., pp. 48ss.

21 Palma, Ciencia y metáforas..., pp. 47, 89ss.

22 Lakoff et Johnson, Metáforas de la..., p. 71.

23 D. Golombek, "Prefacio" en D. Gellon, Habia una vez el átomo. O cómo los científicos imaginan lo invisible. Buenos Aires: UNQuilmes y Siglo XXI, 2007. 
a las ciencias sociales (4), textos destinados a las ciencias formales (9) ${ }^{24}$, y textos cuya temática consiste en una reflexión filosófico-histórico-sociológica sobre las ciencias (5). Para la realización de este trabajo, se seleccionaron ocho (8) textos dedicados a las ciencias naturales. En ellos, se identificaron y caracterizaron las metáforas encontradas en tapas (títulos y composición de imágenes), así como en párrafos escogidos del interior de los libros, según la clasificación ofrecida más arriba.

El abordaje del corpus se lleva a cabo desde una perspectiva multidisciplinar en la que convergen las miradas de especialistas en comunicación, filósofos y didactas de las ciencias naturales. Desde el campo de la Comunicación Social se adopta el enfoque de la CPC desde las representaciones sociales, siguiendo a Cortassa. Desde la Filosofía de las Ciencias, se enmarca en las concepciones actuales herederas de la Nueva Filosofía de las Ciencias ${ }^{25}$; de ahí la referencia a Black, Kuhn, Boyd. Por último, desde la Didáctica de las Ciencias se adopta un enfoque constructivista ${ }^{26}$.

\section{Resultados y discusión}

Los resultados que se exponen a continuación son producto de un análisis que abarca la mayoría de los textos disponibles de esta colección. La selección actual responde al carácter representativo de los elementos teóricos identificables en cada caso: tipo de metáfora, función en el texto y supuestos comunicativos. Presentamos por separado el análisis de las tapas y el de los fragmentos elegidos.

\subsection{Análisis de las tapas}

Lo primero que llama la atención al leer los títulos es su carácter lúdico y, en consecuencia, inevitablemente llamativo. En la mayoría de los casos de la colección CQL y, en especial, en todos los textos seleccionados para este análisis, se trata de metáforas construidas en base a referencias culturales tales como libros, películas, poemas, canciones, de amplio conocimiento popular. Esto es razonable dado que es una colección destinada al público en general: presenta un tema científico al mismo tiempo que llama su atención y se muestra accesible.

Estas metáforas, no obstante, están muy situadas históricamente. La franja etaria que comparte metáforas provenientes de la cultura suele ser definida. Asimismo, si bien se trata en general de metáforas populares, el tipo de interactividad que

24 Utilizamos esta clasificación tradicional entre ciencias formales, naturales y sociales para facilitar la presentación. Somos conscientes de los aspectos problemáticos de esta clasificación.

25 A.R. Pérez Ransanz, Kuhn y el cambio cientifico. México: FCE, 1999.

26 M.J. Rodrigo López et R. Cubero Pérez, "Constructivismo y enseńanza de las ciencias", en F. Perales Palacios et P. Cañal de León (eds.): Didáctica de las ciencias experimentales. Teoría y práctica de la enseñanza de las ciencias. Madrid: Alcoy, 2000, pp. 85-108. 
produce puede diferir según el contexto del lector, llegando incluso a la ineficacia de la metáfora, como se señalará en alguno de los casos.

El título del ejemplar Habia una vez el átomo. O cómo los cientificos imaginan lo invisible ${ }^{27}$ hace referencia a la tradicional fórmula de inicio de los cuentos infantiles y leyendas tradicionales. Esta resonancia con la ficción acompaña al subtítulo, que contradice la imagen habitual sobre la ciencia. Según esta imagen, la ciencia no es producto de la imaginación o la fabulación sino del raciocinio y la investigación metódica. En efecto, se supone que la ciencia 'descubre', 'encuentra', 'establece' hechos probatorios o aspectos de la realidad, pero no los 'imagina'. Sin embargo, en las primeras páginas el lector se enfrenta a una paradoja: "El universo está hecho de átomos. (...) Pero nadie puede decir que ha visto un átomo" ${ }^{28}$. ¿Cómo afirmar que se 'descubre' lo invisible?

La imagen de la tabla periódica es significativa no sólo por la referencia a la clasificación los elementos químicos sino también a su historia: Mendeleiev la propuso con espacios en blanco dando por supuesto que existían elementos en la naturaleza que aún no habían sido 'encontrados'. Además, vemos a dos científicos: uno recostado sobre la tabla periódica recortando la palabra 'elementos' y otro en una postura estereotipada de pensamiento y observando al anterior desde uno de los laterales, imaginando una cadena de átomos -que se infiere lo constituyen-. Esta imagen representa literalmente el subtítulo: el cuerpo se ve como un todo y sus componentes atómicos no se ven, pero se 'imaginan'. El subtítulo aborda la paradoja científica con una construcción comunicacionalmente efectiva y epistemológicamente significativa. En este sentido, refuerza la metáfora literaria y remite a la discusión filosófica entre realismo e instrumentalismo, que en el siglo $\mathrm{XX}$ alcanza un punto álgido entre los físicos ${ }^{29}$.

El título Ahi viene la plaga. Virus emergentes, epidemias y pandemias ${ }^{30}$ hace referencia al popularísimo rock "La plaga" de Robert Blackwell y John Marascalo. El término 'plaga' juega con el sentido al sustituir los términos enumerados en el subtítulo ('virus emergentes', 'epidemias', 'pandemias'). La metáfora es efectiva en sugerir la interacción entre una enfermedad contagiosa o una invasión de animales transmisores de enfermedades por un lado, y un ritmo pegadizo, por el otro. Ambos términos de la interacción están ilustrados, respectivamente, con una figura humana abrigada, con la nariz roja, un termómetro en su boca y los pies dentro de una palangana con agua caliente y por representaciones de

27 Gellon, Habia una vez el átomo.... Cf. portada en http://www.sigloxxieditores.com.ar/ fichaLibro.php?libro=978-987-1220-93-9 (Disponible el 28/09/2018).

28 Gellon, Habia una vez..., pp. 17-18.

29 F. Selleri, El debate de la teoría cuántica. Madrid: Alianza, 1986, pp. 11-54.

30 M. Lozano, Ahi viene la plaga. Virus emergentes, epidemias y pandemias. Buenos Aires: UNQuilmes y Siglo XXI, 2004. Cf. portada en http://www.sigloxxieditores.com.ar/fichaLibro. php?libro=978-987-1105-69-4 (Disponible el 28/09/2018). 
las 'plagas': ratas y mosquitos (metaforizando aviones 'tirabombas'). A pesar de tratarse de una interacción efectiva, la metáfora puede ser ambigua dado que no distingue entre los agentes transmisores de las enfermedades y los efectos sobre la población.

El título Cortar y pegar. Transplantes de órganos y reconstrucción del cuerpo humano $^{31}$ combina lo que podemos llamar dos grandes metáforas. Por un lado, la metáfora mecanicista según la cual el cuerpo humano está compuesto por 'partes extra partes' sustituibles, como en cualquier objeto mecánico o, por usar la denominación que propone Simondon, cualquier objeto técnico abstracto ${ }^{32}$. Resulta interesante que esta metáfora aún funcione, siendo que la mirada mecanicista propia del siglo XVII sobre el cuerpo humano en particular y sobre la biología en general ha sido abandonada en el siglo XX. Por otro lado, la metáfora proveniente de la informática ${ }^{33}$ cuyos conceptos se están instalando ya como una gran metáfora del presente que atraviesa tanto a otras ciencias como a las conceptualizaciones culturales.

'Cortar y pegar' es, en efecto, una operación corriente en muchos programas informáticos, si bien no tiene el sentido exacto de sustituir una parte por otra sino de repetir o cambiar de lugar un texto o representación. El ser 'humano' resulta de integrar diferentes miembros, como si fuera un collage cuyas partes carecen de relación unas con otras: la imagen está compuesta por elementos mecánicos (ruedas, una llave para dar cuerda,) elementos biológicos (una rama, un brazo de pulpo, una hoja) y elementos culturales (una cinta cinematográfica). La conjunción de las dos metáforas tiene así un efecto adicional: el cuerpo humano es concebido como una combinación de elementos orgánicos, mecánicos y electrónicos, a la manera de un cyborg.

En el caso de El huevo y la gallina. Manual de instrucciones para construir un anima ${ }^{\beta 4}$, la metáfora de la construcción en el subtítulo produce una interacción de mecanicista. Y la expresión 'manual de instrucciones' para referir a la constitución genética está muy extendida en la comunicación y en la enseñanza de las ciencias.

Por su parte, el título apela al lugar común que suele ser usado para referirse a un dilema ocioso, aunque en este caso, no se plantea como una disyunción ('el huevo $o$ la gallina') sino como una conjunción ('el huevo $y$ la gallina') ${ }^{35}$.

31 P. Argibay, Cortar y pegar. Transplantes de órganos y reconstrucción del cuerpo humano. Buenos Aires: UNQuilmes y Siglo XXI, 2007. Cf. portada en http://www.sigloxxieditores.com.ar/ fichaLibro.php?libro=978-987-1220-79-3 (Disponible el 28/09/2018).

32 Cf. G. Simondon, El modo de existencia de los objetos técnicos. Buenos Aires: Prometeo, 2008.

$33 \mathrm{La}$ informática incorpora una referencia a los objetos técnicos abstractos, cf. Simondon, El modo de existencia..., pp. 42 ss.

34 G. Gellon, El huevo y la gallina. Manual de instrucciones para construir un animal. Buenos Aires: UNQuilmes y Siglo XXI, 20047. Cf. portada en http://www.sigloxxieditores.com.ar/ fichaLibro.php?libro=978-987-1105-70-0 (Disponible el 28/09/2018).

$35 \mathrm{La}$ introducción del libro hace referencia a la descripción del desarrollo de los huevos de la 
Acompañada por el subtítulo, resuelve el dilema ofreciendo el conocimiento necesario para construir tanto un huevo como una gallina y desplaza la pregunta sobre el origen de la evolución a la genética.

El título Una tumba para los Romanov. Y otras historias con $A D N^{36}$ remite al hecho histórico de la identificación de los cuerpos de la familia real rusa que concluyó en 2007, análisis de ADN mediante. Esta metáfora supone que tales acontecimientos son de amplio conocimiento -supuesto que no es del todo fundado-. Por ese motivo, la metáfora podría no cumplir con la interacción que se pretende debido al desconocimiento del caso mencionado, sobre todo teniendo en cuenta que la primera edición del libro es anterior a la difusión de la noticia sobre la resolución del 'misterio' del paradero e identificación de los cuerpos de la familia Romanov. El subtítulo hace una referencia literaria similar a la expresión 'Había una vez' del texto sobre los átomos: anuncia el relato de una o más historias y repite el efecto extrañador con respecto a lo que se espera del conocimiento científico.

En la ilustración, la imagen del científico y la hélice recortadas remite a los procesos enzimáticos que se utilizan en las técnicas destinadas a identificación mediante ADN. La interacción puede no resultar productiva dado que no tiene en cuenta la posible distancia epistémica entre el científico y el lego ${ }^{37}$.

El título Bio... ¿qué? Biotecnología, el futuro llegó hace rato ${ }^{38}$ imita la expresión coloquial de completar una palabra difícil o desconocida con un '¿qué?'. El subtítulo despierta el eco de un tema de rock de la banda argentina 'Patricio Rey y sus Redonditos de Ricotta'. La metáfora sugiere que los avances en biotecnología se han desarrollado hasta el momento a las espaldas del gran público y que este libro los dará a conocer. Con esta metáfora, el científico se posiciona a sí mismo en el lugar no sólo de comunicador sino, de alguna manera, de promotor de la cultura científica ${ }^{39}$. De esta manera, participa de la discusión actual acerca de la democratización del conocimiento científico y la participación del público en las decisiones relativas a la ciencia y la tecnología.

El título La química está entre nosotros. De qué están hechas las cosas (átomo a

gallina y otras aves en Historia de los animales de Aristóteles, si bien la expresión se usa habitualmente para parodiar dilemas metafísicos insolubles.

36 R. Alzogaray, Una tumba para los Romanov. $Y$ otras historias con ADN. Buenos Aires: UNQuilmes y Siglo XXI, 2012. Cf. portada en http://www.sigloxxieditores.com.ar/fichaLibro. php?libro=978-987-629-217-7 (Disponible el 28/09/2018).

37 Cortassa, “Del déficit al diálogo...”, pp. 47-72.

38 A. Díaz, Bio... ¿qué? Biotecnología, el futuro llegó hace rato. Buenos Aires: UNQuilmes y Siglo XXI, 2005.Cf. portada en http://www.sigloxxieditores.com.ar/fichaLibro.php?libro=987-1220-29-4 (Disponible el 28/09/2018).

39 J.A. López Cerezo et J.L. Lujan, “Cultura Científica y Participación Formativa”, en F.J. Rubia et al. (eds.): Percepción Social de la Ciencia. Academia Europea de Ciencias y Artes/UNED, 2004. 
átomo y molécula a molécula) ${ }^{40}$ juega con la presencia inadvertida de los átomos de que está compuesta la materia 'parte por parte' como explicita la expresión entre paréntesis del subtítulo. Para algunos, esta expresión también remite a los versos del poema 'Cantares' de Antonio Machado, "Caminante no hay camino/se hace camino al andar/golpe a golpe, verso a verso".

La imagen es compleja y resignifica al título. Muestra a un científico absorbido en la lectura de una tabla periódica de la que se desprenden elementos. Frente a él hay un personaje en pose seductora sentado sobre una máquina de la que salen fórmulas químicas, representaciones de moléculas y gases - pero el científico no la ve-. Así, la química (tabla periódica) está 'entre' ellos. Además, aparecen instrumentos clásicos de laboratorio y más fórmulas y moléculas.

\subsection{Análisis de fragmentos seleccionados}

Como se dijo más arriba, la interacción se puede suponer en todas las categorías de metáforas. A los efectos de este trabajo, nos limitaremos solamente a metáforas comprendidas en el tercer grupo de la clasificación propuesta, a saber, según el tipo y alcance de la operación conceptual y la producción de sentido. Presentamos a continuación tres clases de ejemplos: metáforas en las que la comparación es explícita; metáforas en las que un término se sustituye por otro existente o no existente; metáforas producidas mediante la personificación.

a) Metáforas explícitas de comparación

\section{Ejemplo 1}

Imaginemos un ómnibus que sale de la estación sin pasaje. Durante el recorrido va recogiendo pasajeros, y este proceso (el ascenso de individuos) se podría medir tomando el número de éstos en un instante dado. Al principio, este número aumenta a medida que pasa el tiempo. Pero en algún momento se empieza a dar otro proceso: el descenso de pasajeros. A mitad del recorrido total puede suceder que la cantidad de pasajeros se mantenga constante por un largo tiempo, pero esto no indica que ya no suba nadie más. Dicho de otro modo, se puede alcanzar un estado en el que la velocidad de ascenso, si se toma el número de pasajeros que ascienden por hora, es igual a la de descenso, es decir, a la cantidad de viajeros que descienden en ese mismo lapso. Bajemos del ómnibus y entremos al laboratorio ${ }^{41}$.

Esta metáfora describe el dinamismo en química a través del movimiento de los electrones mediante una comparación explícita con los ascensos y descensos de los pasajeros durante un trayecto en ómnibus. El ómnibus refiere al átomo

40 J. Andrade Gamboa et H. Corso, La quimica está entre nosotros. De qué está hechas las cosas (átomo a átomo y molécula a molécula). Buenos Aires: UNQuilmes y Siglo XXI, 2013. Cf. portada en http://www.sigloxxieditores.com.ar/fichaLibro.php?libro=978-987-629-300-6 (Disponible el 28/09/2018).

41 Andrade Gamboa et Corso, La química está..., p. 44. 
mientras que los pasajeros son los electrones. El ascenso y descenso de pasajeros representa el movimiento de los electrones. Y el objetivo es mostrar que más allá de estos movimientos la cantidad de pasajeros sobre el ómnibus en un lapso dado se mantiene constante. La metáfora recurre a una situación cotidiana fácilmente interpretable por cualquier lector. No obstante, a pesar de que se trata de una comparación explícita, no se aclaran en ella las correspondencias a las que alude. Asimismo, la interacción que propone se puede denominar 'global' en el sentido que no pretende provocar entre los electrones y las personas o el átomo y el ómnibus una interacción conceptual que trascienda la idea de 'cosas' que se suman o se restan de una cantidad dada. En este sentido, la comparación podría tener el mismo efecto si se construyera a partir de cualquier otra situación en la que se sumen y resten objetos durante un determinado trayecto. El carácter global de la metáfora limita su contenido cognitivo.

\section{Ejemplo 2}

Las proteínas de cubierta pueden interactuar con otras proteínas de la célula huésped (la célula que va a ser infectada), de manera que esta interacción determina la capacidad del virus para reconocer y unirse a un determinado tipo de célula. La interacción mencionada es del tipo de llave y cerradura. La proteína del virus (la llave) tiene una forma que es prácticamente la complementaria de la forma de la proteína de la célula (la cerradura) ${ }^{42}$.

La metáfora de la llave y la cerradura para representar la acción enzimática es de uso extendido en los textos de biología. A diferencia del Ejemplo 1, la correspondencia a la que alude (llave-proteína del virus, cerradura-proteína de la célula) está explicitada, lo que favorece la interacción que busca provocar. Asimismo, cualquier persona entiende que una llave y una cerradura 'encajan'. La interacción de esta metáfora se amplifica teniendo en cuenta que no cualquier llave abre cualquier cerradura; del mismo modo si el virus no tiene la estructura adecuada, no logra infectar la célula.

Se puede agregar que además de la comparación este párrafo contiene una personificación del virus al que se otorga la capacidad de "reconocer" y "unirse" a un tipo de célula aun cuando la acción del virus no es 'intencional'. Esta personificación produce una interacción diferente de la comparación analizada, dado que las llaves no 'reconocen' por sí mismas a las cerraduras.

b) Sustituciones

\section{Ejemplo 3}

Luego demostraron que dicho código es universal, esto es, que desde las bacterias hasta los seres humanos, pasando por levaduras, hongos, insectos, 
plantas y animales, todos poseemos las mismas letras (A, C, G y T), las mismas moléculas químicas gracias a las cuales conservamos la información genética. (...) El otro descubrimiento fue el de las 'enzimas de restricción', que son enzimas que cortan el $\mathrm{ADN}$ en lugares específicos, ya que reconocen secuencias (letras) muy específicas (por ejemplo, la enzima EcoRI reconoce y corta sólo la secuencia GAATTC). Son mediáticamente llamadas 'tijeras moleculares' ${ }^{43}$.

\section{Ejemplo 4}

Hoy sabemos que todos los seres que viven o vivieron sobre la tierra han sido construidos siguiendo las instrucciones contenidas en su ADN. ¿Qué son los genes? ¿Qué es el código genético? ${ }^{44}$.

En los Ejemplos 3 y 4, la sustitución ocupa el lugar de un término inexistente. En efecto, el término 'código' sustituye un vacío lingüístico para referirse a la combinación de tres nucleótidos que produce un aminoácido. Se trata de una metáfora constitutiva de teoría. Desde otro punto de vista, es una metáfora de interacción entre campos científicos o 'migrante' ${ }^{25}$ dado que el término se toma de la teoría de la información/comunicación.

En una de sus acepciones, 'código' significa "sistema de signos y reglas que permite formular y comprender mensajes secretos" (DRAE) ${ }^{46}$. A pesar de que los científicos tal vez no hayan elegido el término por esta connotación, su conocimiento implícito aporta a la metáfora un carácter de 'nuevo descubrimiento' propio del momento histórico de la constitución de la teoría.

\section{Ejemplo 5}

Las plantas son bichos inteligentes. Mientras nosotros necesitamos de todo para ir andando en dos patas por el mundo, se las arreglan con poco y nada: algunos minerales, agua, un poco de sol. No por nada están en el principio de todo, hasta en el comienzo del Génesis ${ }^{47}$.

En este Ejemplo 'bichos' reemplaza a un término existente como 'organismo' o 'ser vivo' y, en combinación con que "nosotros ... andamos en dos patas por el mundo", se refiere metafóricamente a los seres humanos también como 'bichos'. La sustitución se complementa con una personificación que le atribuye inteligencia a los vegetales. La composición metafórica total no provoca interacción cognitiva relevante; en todo caso, el efecto interactivo remite a un uso

43 Díaz, Bio... ¿qué?..., p. 23.

44 Alzogaray, Una tumba para..., p. 14.

45 G. Ciapuscio, "De metáforas durmientes, endurecidas y nómades: un enfoque lingüístico de las metáforas en la comunicación de la ciencia", en Arbor Ciencia, Pensamiento y Cultura vol 187 (2011), pp. 89-98.

46 Diccionario de la Real Academica Espańola, disponible en www.rae.es.

47 D. Golombek et P. Schwarzbaum, El cocinero cientifico. Cuando la ciencia se mete en la cocina. Buenos Aires: UNQuilmes y Siglo XXI, 2004, p. 51. 
popular del término 'bicho' en expresiones como 'bicho raro' o 'bicho inteligente' que sí provoca la complicidad con el lector. La referencia al Génesis es imprecisa desde el punto de vista evolutivo (porque las primeras 'plantas' eran algas) pero potencia la personificación asociando la inteligencia a la calidad de ser los primeros organismos complejos 'vivos'.

\section{c) Personificaciones}

\section{Ejemplo 6}

Brown descubrió este fenómeno al estudiar granos de polen, los cuales debían observarse con cuidado para determinar claves morfológicas para la clasificación de especies vegetales. Advirtió entonces que los granos de polen suspendidos en líquidos bailaban alocadamente sin ton ni son. Se preguntó si se trataba de un movimiento motorizado internamente por los propios granos, pero logró determinar que la misma danza se había manifiesta en motas de polvo o partículas de ceniza. Concluyó que el movimiento se debía, de alguna forma, al líquido, aunque este movimiento, sorprendentemente, parecía o cesar nunca ${ }^{48}$.

\section{Ejemplo 7}

No todo lo que somos está determinado por el gobierno de nuestros núcleos celulares... Nuestros núcleos celulares contienen las instrucciones para nuestra construcción, pero esas instrucciones son relativamente flexibles y su producto depende de cómo, dónde y cuándo son ejecutadas ${ }^{49}$.

En los ejemplos 6 y 7, las expresiones 'danzar' y 'gobierno' son también sustituciones de términos existentes, en este caso, términos comunes. No obstante, existen dos diferencias entre estas sustituciones y la del Ejemplo 5. La primera consiste en que los términos sustituidos en el Ejemplo 5 ('organismo', 'ser vivo'), aunque usados en la vida cotidiana, tienen también un eco científico; en cambio, en los Ejemplos 6 y 7 se sustituyen términos comunes (moverse por danzar y regulación por gobierno). La segunda es que estas sustituciones dan como resultado una interacción metafórica mediante la personificación de los granos de polen y el núcleo celular, mientras que en el Ejemplo 5 la personificación se agrega a la sustitución.

En el ejemplo 6 se sustituye la expresión verbal 'se mueven' por 'bailan' y el resultado 'movimiento' por 'danza'. Se suma a esta metáfora la expresión cultural corriente 'sin ton ni son'. La interacción que provoca este conjunto metafórico, más que remitir a un movimiento voluntario por parte de los granos de polen, remite a la belleza y el asombro experimentado por el científico. En este sentido, constituye un recurso retórico del comunicador que promueve una actitud

48 Gellon, Habia una vez el átomo..., p. 22.

49 Gellon, El huevo y la gallina..., p. 37. 
cognitiva frente a la naturaleza y el desarrollo de teorías en línea con el lugar común de la curiosidad como rasgo propio del investigador. Cabe señalar que el procedimiento cognitivo de construcción de esta metáfora es analógico.

El Ejemplo 7, por su parte, personifica las determinaciones causales de los núcleos celulares en la metáfora del 'gobierno'. En el fondo, la comprensión de los procesos que describe la frase se alcanzaría de igual modo si se omitiera la expresión 'el gobierno de'. La causalidad natural no supone una teleología ni una intencionalidad. Sin embargo, sustituir el término 'regulación' por 'gobierno' agrega las ideas de autoridad y planificación en la interacción metafórica. La observación sobre la flexibilidad de las instrucciones refuerza la personificación al sugerir que es el núcleo celular quien decide 'cómo, cuándo y dónde' ejecutar esas instrucciones. Si bien esta sustitución es bastante corriente, su efecto cognitivo excede la descripción de los procesos celulares y remite de alguna manera al lugar común de la 'sabiduría' de la naturaleza -metáfora de origen en la cultura que también es de uso habitual-.

\section{RECOMENDACIONES}

Este análisis de algunos ejemplares de la colección CQL pone de relieve la presencia y el valor de la metáfora según cuatro funciones: con fines informativos, con fines didácticos, en la constitución de las teorías científicas, o de acercamiento al lector pero sin interacción cognitiva significativa.

En segundo lugar, es relevante subrayar una vez más que los textos seleccionados para el corpus han sido escritos por científicos y no por comunicadores. Así como cuando se dirige a sus pares adopta una retórica con rasgos definidos por la comunidad académica, en su rol de comunicador el científico adopta un estilo que supone adecuado para llegar al público lego. Si bien las metáforas no están excluidas por completo de la retórica académica, a partir de una lectura más extensiva de esta colección cabe concluir que el científico supone que la abundancia de procedimientos metafóricos es adecuada para la retórica comunicativa. Prueba de ello son las metáforas analizadas cuyo contenido cognitivo es menor con respecto a su valor comunicativo. En este sentido, hay que advertir que una metáfora seleccionada sólo por hacer más 'amigable' un texto científico corre el riesgo de resultar contraproducente con respecto a su propia meta, esto es, la transmisión de un conocimiento, y acentúa el supuesto de carencia propio del modelo del déficit.

En tercer lugar, los datos de la colección no informan sobre la mediación de una interfaz ${ }^{50}$, más que en el diseño de las tapas. Éstas han sido realizadas por profesionales pertenecientes a la Universidad de Quilmes. La interacción entre las ilustraciones y los procedimientos metafóricos que dan lugar a los títulos permite

50 Cf. Cortassa, "Del modaelo del déficit...”. 
suponer una colaboración entre aquéllos y los científicos a cargo de cada texto (aunque poco podemos decir sobre el alcance de esta colaboración).

Por último, aclaramos que la intención de nuestras investigaciones en la comunicación de las ciencias no es ningún momento comparar la labor que realizan los científicos que, en ocasiones bajo cierta presión de sus lugares de trabajo, se enfrentan a la tarea de comunicar los procedimientos y los resultados de sus investigaciones a un público amplio, con la tarea de los comunicadores especializados en ciencias. Al margen de que no es el objeto de este trabajo, consideramos que discutir quién está mejor calificado para llevar a cabo la tarea de la comunicación de las ciencias no implica un aporte relevante a las problemáticas de esta disciplina en general, ni de la función de las metáforas en la producción y comunicación del conocimiento en particular. Con todo, es necesario subrayar la tensión que enfrentan ambos, científicos y comunicadores, al momento de difundir el conocimiento -una tensión que difiere para cada uno y, a su vez, de la del docente-. El científico ha elaborado el conocimiento, ha desarrollado por sí mismo las investigaciones. Y, cuando se propone asumir el rol de comunicador, seguramente intenta llegar al público sin 'traicionar' la precisión y especificidad del conocimiento -lo que no sería justo para ninguno de los dos-. En los textos analizados, los procedimientos metafóricos son un recurso que pretende contribuir a mantener ese delicado equilibrio, aunque no siempre con éxito. El comunicador elabora sus columnas luego de un diálogo con el investigador o con sus producciones. Pero, a diferencia del investigador, tiene más conciencia de la relevancia de escribir desde el modelo de las tres D y maneja las herramientas comunicativas para llegar a diferentes audiencias. Tanto para el científico como para el comunicador las metáforas son un recurso comúnmente utilizado cuya potencia cognitiva merece ser analizada y tenida en cuenta.

En el fondo de estas tensiones subyace la asimetría científico/público y la relevancia de la interfaz que a veces asume el científico y a veces el comunicador. El análisis muestra que, en definitiva, la tarea asumida por los científicos como comunicadores no es sencilla. En el uso de la metáfora aún se observa que no se prioriza su potencial cognitivo, como si éste fuera excluyente de su capacidad comunicativa. La consecuencia es una fluctuación entre el modelo del déficit y el modelo del diálogo. Dar por supuesto que no existe asimetría alguna entre el público y el científico, tanto como dar por supuesto que el científico, por conocer, puede también comunicar, redundaría en una ilusión de comunicación. Evitar este obstáculo requiere el trabajo sobre las metáforas, entre otros elementos constitutivos del conocimiento, así como sobre la teoría de la comunicación pública de las ciencias. 